\title{
Providing application-specific climate projections datasets: CSIRO's Climate Futures Framework
}

\author{
J.M. Clarke $^{a}$, P.H. Whetton ${ }^{a}$ and K.J. Hennessy ${ }^{a}$ \\ ${ }^{a}$ Climate Adaptation Flagship, CSIRO Marine and Atmospheric Research, Aspendale, Victoria, Australia
}

Email: John.Clarke@,csiro.au

\begin{abstract}
CSIRO has been developing climate projections since the 1980s and released national projections for Australia in 1988, 1992, 1996, 2001 and 2007. As these were designed communicate nation- and state-wide changes to a range of users, the projections focused on individual climate variables, such as temperature, with a range of uncertainty derived from multiple climate models. Over this time, CSIRO has also been involved in many impact assessments with collaborators and clients. These usually require projections tailored for specific applications. Such applications require internally consistent combinations of climate variables such as those based on output from individual models.

However, many end-users of projections find the complexity (including the range of uncertainty) difficult to deal with. There are projections from up to 24 global climate models (GCMs), up to six emission scenarios, and around a dozen climate variables. Given limited resources, end-users often seek a narrower range of projections for their applications.
\end{abstract}

CSIRO Marine and Atmospheric Research has developed a novel approach to deal with this issue in a way that is tailored to the specific needs of applications. The Climate Futures Framework allows climate scientists, in close consultation with end-users, to provide simplified projections while still addressing uncertainty. This approach also facilitates the selection of a sub-set of climate models from which internally consistent data can be obtained for multiple variables.

The Climate Futures Framework classifies the GCM projected changes into pre-defined categories (called climate futures) defined by two climate variables - commonly the change in annual mean surface temperature and annual average rainfall. Each climate future is assigned a relative likelihood based on the number of climate models that fall within that category. For example, if 12 of 24 models fall into the "Warmer - Drier" climate future, it is given a relative likelihood of $50 \%$.

In most cases, this results in a small number of climate futures, each with a relative likelihood. It is then possible to further simplify the projections using a risk assessment approach (where risk = consequence $\mathrm{x}$ likelihood). In consultation with the decision makers, key climate futures that directly influence the decision-making are identified for further assessment. Any other climate futures that will not affect decision-making can be ignored for the purposes of the particular impact assessment.

Once the relevant climate futures and key variables have been identified, multi-variate ranking is used to determine the most representative model(s) from each climate future. This subset of models can then be used to generate internally consistent datasets.

CSIRO has been using the Climate Futures Framework to provide climate change projections and associated datasets to clients within and outside Australia since 2009. Although focussed research into client attitudes to the approach is yet to be undertaken, initial feedback suggests it is a useful aid to understanding projected changes and their associated uncertainty, while simplifying the selection of a small number of models for use in risk assessment.

The Framework also offers other benefits, including improved communication of projections to a wide audience. This paper will focus on its use in providing application-specific datasets.

Keywords: Climate Futures Framework, climate projections, impact assessment, adaptation, climate change, scenarios 


\section{INTRODUCTION}

Demand for climate projections data has increased in recent years from practitioners interested in understanding possible impacts of climate change on biophysical and social systems. For example, the number of requests received by CSIRO Marine and Atmospheric Research for projections and related data increased from around 4 requests per month in late 2008 to almost 9 in mid-2011. The requests have also become more complex with many clients seeking localised, multi-variate projections applied to an appropriate observed dataset, often in the form of a time-series (e.g. for use in an impacts model).

In order to maximise the robustness of the resultant impact assessment, it is essential to ensure the projections data are internally consistent. That is, the values for all variables must be consistent with each other (physically plausible).Values obtained from a single GCM have this 'internal consistency'. Combining results from multimodel PDFs based on single variables do not have this consistency.

Appropriate sampling of uncertainty is a fundamental part of risk assessment. Using data from 24 GCMs (23 from CMIP3 plus the CSIRO-Mk3.5 model) is often unviable for end-users with limited resources. Selecting a small number of models should be based on criteria that limit bias and are as objective as possible. While it may be tempting to use a single "mid-range" model, this overlooks other out-lying and potentially important future climates. A common approach to this issue has been to select a small number of 'best' climate models based on their ability to represent the current climate (e.g. Pitman and Perkins 2008; Smith and Chandler 2010). This approach suffers from a lack of consensus on how to assess the 'best' models and does not account for the need to represent the range of uncertainty among the full suite of available model projections.

The Representative Climate Futures (RCF) framework (Whetton et al. submitted), hereafter referred to as the Climate Futures Framework, overcomes these limitations by classifying the projected changes from the full suite of climate models into classes defined by two climate variables (usually the change in annual mean temperature and rainfall - see Figure 1). Relative likelihoods are assigned to each class or climate future based on the number of climate models that fall within that category. For example, if 12 of 24 models fall into the "Warmer - Drier" climate future, it is given a relative likelihood of 50\%. A subset of models can be selected to represent any or all of the climate futures. A software tool has been developed to facilitate use of the framework at a regional level (but not as yet to deal with the less common, but more challenging multiregional case). The tool provides projections for up to 11 climate variables, three time periods and six emissions scenarios (Nakićenović and Swart 2000). In this paper, we demonstrate the application of the framework (via the tool) to a hypothetical Australian case study - rainfall harvesting in Perth.

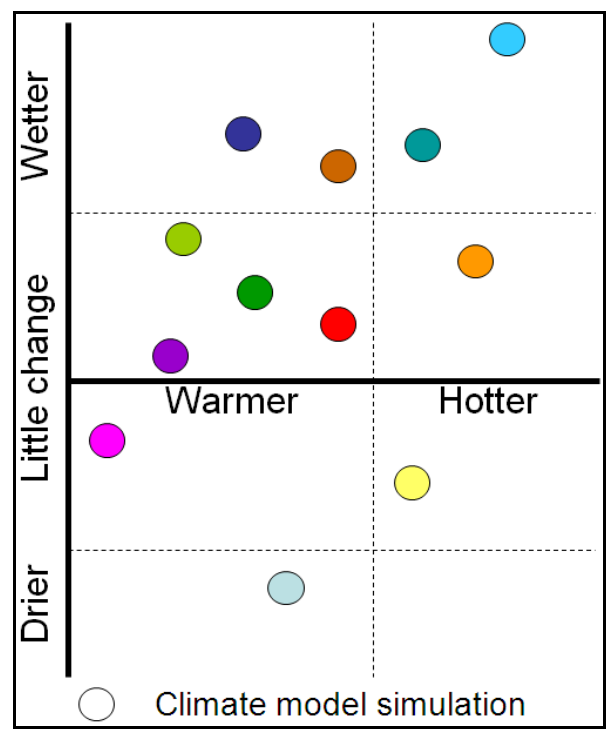

Figure 1 Stylised scatter plot representing classification of GCM projected changes into climate futures 


\section{HYPOTHETICAL CASE STUDY: RAINFALL HARVESTING IN PERTH}

To illustrate the approach, projected changes in key climate variables will be produced for a grid-square (approximately $500 \times 500 \mathrm{~km}$ ) encompassing Perth $\left(31^{\circ} 57^{\prime} 8^{\prime \prime} \mathrm{S}, 115^{\circ} 51^{\prime} 32^{\prime \prime} \mathrm{E}\right)$. This is normally undertaken as a consultative process with the end-user of the projections data - typically a decision maker undertaking a climate change risk assessment.

\subsection{Step 1: Generate the climate futures}

In consultation with the client, the time-period, emissions scenarios and key climate variables are determined. These are then used to generate the climate futures. For this example, we will explore the changes in rainfall, temperature and potential evapotranspiration (wet areal evapotranspiration, sensu Morton 1983) in 2050 under two emissions scenarios: B1 and A1FI representing low and high emissions, respectively (Nakićenović and Swart, 2000). As evapotranspiration change is strongly correlated with mean temperature change (0.9 for the Australian region; Whetton et al. submitted, Table 2), it is appropriate to use temperature as one of the classifying variables, the other being rainfall (Figure 2). As a general principle, the full suite of available models should be used to generate the climate futures to ensure the full range of uncertainty as given by GCMs is explored. Since not all models provide data on potential evapotranspiration, using mean temperature as a surrogate permits the use of all models (the availability of data influences model selection later in the process).

The relative likelihood classes used and their colour codes are shown in Table 1.

Table 1 Likelihood categories and colour codes used in the climate futures matrix

\begin{tabular}{|c|c|c|}
\hline Likelihood & & Proportion of models \\
\hline Not projected & & 0 \\
\hline Very low & & $<10 \%$ \\
\hline Low & & $>10$ to $33 \%$ \\
\hline Moderate & & $>33$ to $66 \%$ \\
\hline High & & $>66$ to $90 \%$ \\
\hline Very high & $>90 \%$ \\
\hline
\end{tabular}

\begin{tabular}{|c|c|c|c|c|c|c|c|}
\hline \multicolumn{8}{|c|}{ Climate Futures for region centred on $32.5^{\circ} \mathrm{S}, 116.5^{\circ} \mathrm{E}$} \\
\hline \multicolumn{8}{|c|}{$2050 \mathrm{~A} 1 \mathrm{FI}$} \\
\hline & & \multicolumn{6}{|c|}{ Surface Temperature - Annual ${ }^{\circ} \mathrm{C}$ ) } \\
\hline & & \multicolumn{2}{|c|}{$\begin{array}{c}\text { Slightly } \\
\text { Warmer } \\
<0.50\end{array}$} & $\begin{array}{l}\text { Warmer } \\
0.50 \text { to } 1.50\end{array}$ & $\begin{array}{c}\text { Hotter } \\
1.50 \text { to } 3.00\end{array}$ & \multicolumn{2}{|c|}{$\begin{array}{l}\text { Much Hotter } \\
>3.00\end{array}$} \\
\hline \multicolumn{2}{|r|}{$\begin{array}{c}\text { Much Drier } \\
<-15.00\end{array}$} & & & & Likelihood: 12 of 24 models ( $50 \%$ ) & \multicolumn{2}{|c|}{ Likelihood: 1 of 24 models ( $4 \%$} \\
\hline \multirow{4}{*}{$\begin{array}{c}\text { Rainfall - } \\
\text { Annual } \\
(\% \text { change })\end{array}$} & $\begin{array}{l}\text { Drier } \\
-15.00 \text { to } \\
5.00\end{array}$ & & & & Likelihood: 6 of 24 models ( $25 \%$ ) & \multicolumn{2}{|c|}{ Likelihood: 2 of 24 models ( $8 \%$} \\
\hline & \begin{tabular}{|c|} 
Little \\
Change \\
-5.00 to 5.00 \\
\end{tabular} & & & Likelihood: 1 of 24 models ( $4 \%$ ) & Likelihood: 1 of 24 models ( $4 \%$ ) & & \\
\hline & $\begin{array}{c}\text { Wetter } \\
5.00 \text { to } \\
15.00\end{array}$ & & & & Likelihood: 1 of 24 models ( $4 \%$ ) & & \\
\hline & $\begin{array}{l}\text { Much } \\
\text { Wetter } \\
>15.00\end{array}$ & & & & & & \\
\hline \multicolumn{8}{|c|}{$2050 \mathrm{~B} 1$} \\
\hline & & & \multicolumn{5}{|c|}{ Surface Temperature -Annual $\left({ }^{\circ} \mathrm{C}\right)$} \\
\hline & & & & $\begin{array}{c}\text { Slightly Warmer } \\
<0.50\end{array}$ & $\begin{array}{c}\text { Warmer } \\
0.50 \text { to } 1.50\end{array}$ & $\begin{array}{c}\text { Hotter } \\
1.50 \text { to } 3.00\end{array}$ & \begin{tabular}{|c|} 
Much Hotter \\
$>3.00$
\end{tabular} \\
\hline \multirow{5}{*}{$\begin{array}{l}\text { Rainfall - Annual } \\
\text { (\% change) }\end{array}$} & \multicolumn{2}{|c|}{$\begin{array}{c}\text { Much Drier } \\
<-15.00\end{array}$} & & & & & \\
\hline & \multicolumn{2}{|c|}{$\begin{array}{c}\text { Drier } \\
-15.00 \text { to }-5.00\end{array}$} & & elihood: 2 of 24 models ( $8 \%$ ) & Likelihood: 7 of 24 models ( $29 \%)$ & & \\
\hline & \multicolumn{2}{|c|}{$\begin{array}{l}\text { Little Change } \\
5.00 \text { to } 5.00\end{array}$} & & lihood: 3 of 24 models ( $12 \%$ ) & Likelihood: 12 of 24 models ( $50 \%$ ) & & \\
\hline & \multicolumn{2}{|c|}{$\begin{array}{c}\text { Wetter } \\
5.00 \text { to } 15.00\end{array}$} & & & & & \\
\hline & \multicolumn{2}{|c|}{$\begin{array}{c}\text { Much Wetter } \\
>15.00\end{array}$} & & & & & \\
\hline
\end{tabular}

Figure 2 Climate Futures 'matrices' for the 500 x $500 \mathrm{~km}$ region encompassing Perth, classified by changes in annual surface temperature and rainfall and showing relative likelihoods based on model density 
Figure 2 (bottom) shows the projected changes for the low emissions future range from 'Slightly Warmer' to 'Warmer' and 'Little Rainfall Change' to 'Drier'. It also shows that a future with little change in rainfall is relatively more likely (15 models) than a drier future ( 9 models), although the difference is not great. In contrast, Figure 2 (top) shows that the projected changes under the high emissions scenario give much greater spread, with seven climate futures. However, five of these have very low relative likelihoods, with only one or two models supporting the futures. In addition, the model spread clearly favours a future with reduced rainfall. In each case, a relative 'most likely' climate future (combining rainfall and temperature changes) can be identified. In addition, the lower likelihood climate futures are readily identified and some or all of these may be of relevance to a particular risk assessment.

\subsection{Step 2: Define application-relevant cases and examine the model results}

For a given risk assessment, it is usually possible to identify a subset of the climate futures that represent 'cases' that will directly affect the decisions to be made. Each of these has one or more associated 'consequences' (identified by the end-user) and relative likelihood (derived from its climate future). In this example, the key climate futures are called the 'most likely', 'worst' and 'best' cases.

The 'most likely' case is the climate future represented by the greatest number of models. This is not always a clear-cut choice. Here we define the 'most likely' climate future as that which contains more than 1/3 of the total number of models, where the number must be at least 3 greater than the next most populous climate future. Note that sometimes it is not possible to describe any one of the projected climate futures as 'most likely'.

The 'best' case definition is dependent on the details of the risk assessment being undertaken. In this example, the best case will be defined as that climate future that would result in the highest rainfall (highest priority) and lowest evaporation (in other words, the 'wettest and least-hot'). This may minimise the need for investment in additional water capture infrastructure.

The 'worst' case is also dependent on the risk assessment. For this example, the worst case will be defined as the climate future that would result in the least rainfall (highest priority) and highest evaporation (in other words, the 'driest and hottest'). Such a future is likely to result in increased investment in water capture and storage infrastructure.

In this example we have used all available (24) GCMs to generate the climate futures. In some regions it may be desirable to reject some models based on a multi-factor analysis of model performance (e.g. Irving DB et al. submitted; Smith and Chandler 2010).

The key climate futures for each of the selected cases are shown in Table 2 with notes on consequence and likelihood.

Table 2 Key climate futures for a hypothetical rainwater harvesting assessment for Perth in 2050

\begin{tabular}{|c|c|c|c|c|c|}
\hline \multirow{2}{*}{ Case } & \multirow{2}{*}{ Consequence } & \multicolumn{2}{|c|}{ Low Emissions (B1) } & \multicolumn{2}{|c|}{ High Emissions (A1FI) } \\
\hline & & Climate Future & Likelihood & Climate Future & Likelihood \\
\hline 'Best' & $\begin{array}{l}\text { Least investment in } \\
\text { new infrastructure }\end{array}$ & $\begin{array}{c}\text { Slightly Warmer } \\
\text { and Little Rainfall } \\
\text { Change }\end{array}$ & Low (2 models) & Hotter and Wetter & Very Low (1 model) \\
\hline 'Worst' & $\begin{array}{l}\text { Greatest investment } \\
\text { in new infrastructure }\end{array}$ & Warmer and Drier & Low (7 models) & $\begin{array}{l}\text { Much Hotter and } \\
\text { Much Drier }\end{array}$ & Very Low (1 model) \\
\hline 'Most Likely' & $\begin{array}{c}\text { Usually intermediate } \\
\text { impact, although not } \\
\text { always }\end{array}$ & $\begin{array}{l}\text { Warmer and Little } \\
\text { Rainfall Change }\end{array}$ & $\begin{array}{l}\text { Moderate (12 } \\
\text { models) }\end{array}$ & $\begin{array}{l}\text { Hotter and Much } \\
\text { Drier }\end{array}$ & $\begin{array}{l}\text { Moderate (12 } \\
\text { models) }\end{array}$ \\
\hline
\end{tabular}

Each of the key climate futures can now be examined in more detail. For illustrative purposes, we will just focus on the high emissions scenario (A1FI). In practice, the steps would be repeated for the low emissions scenario.

Once the key climate futures have been identified, changes in all variables of interest can be explored - in this example, we require seasonal changes in mean temperature, rainfall and potential evapotranspiration. The tool displays the selected variables within the climate futures matrix. The output is shown in Figure $3-$ in order to save space, just the key climate futures have been extracted from the display 


\subsection{Step 3: Identify a representative model for each key climate future and generate internally consistent data}

Ideally, results from all models within each climate future would be used in the risk assessment. However, in order to ensure the data used are internally consistent, this requires the risk assessment process to be undertaken separately for each model. In this example that would be 12 times for the 'most likely' and one each for the 'best' and 'worst' cases. For many end-users, this is not practicable due to time or resource constraints. However, once the range of projections has been sub-divided into climate futures, a range of methods can be used to choose one or more representative models from each climate future. The climate futures tool does this using a statistical multi-variate ranking technique (Kokic et al. 2002). The results of the ranking for the 'most

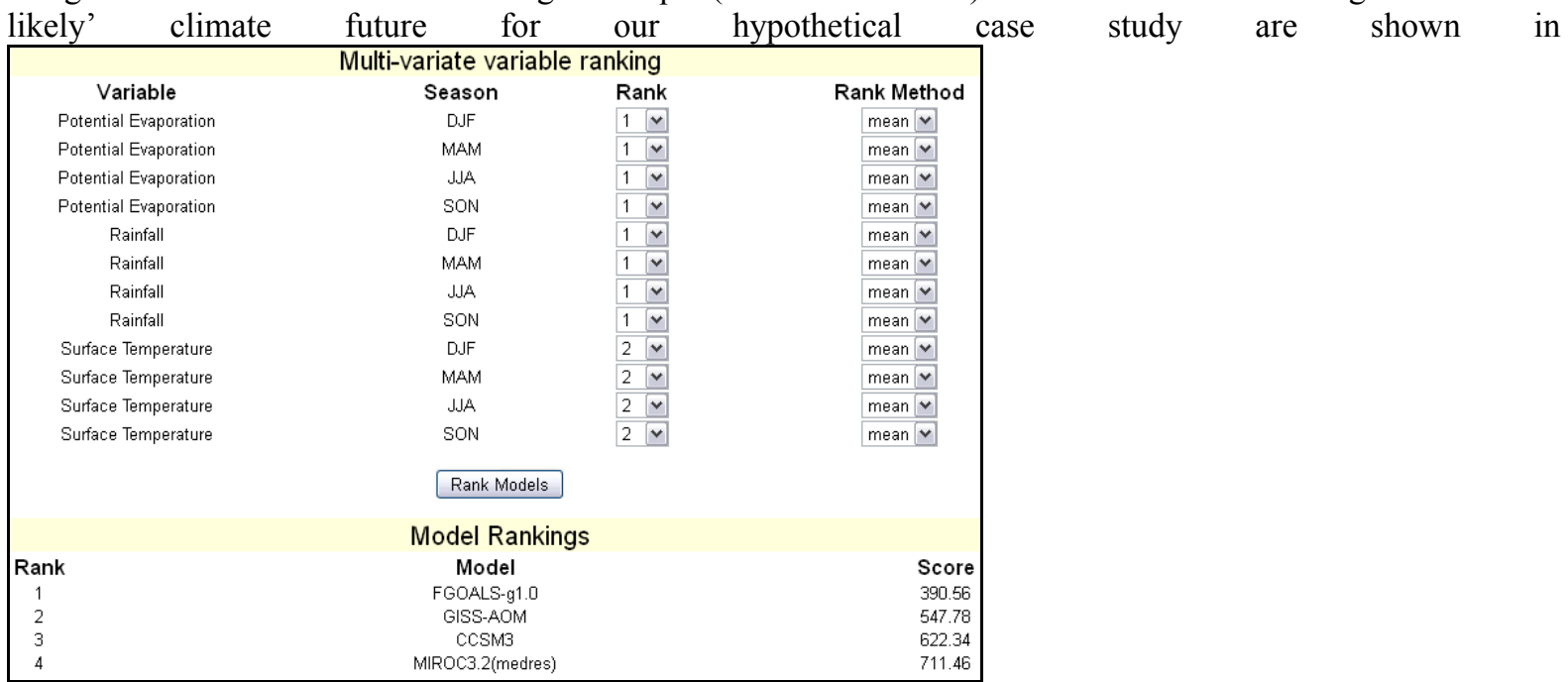

Figure 4 . Note that the method ignores any model which cannot provide all of the data requested - hence only 4 of the 12 models are ranked. 
Clarke et al. Providing application-specific climate projections datasets: Climate Futures Framework

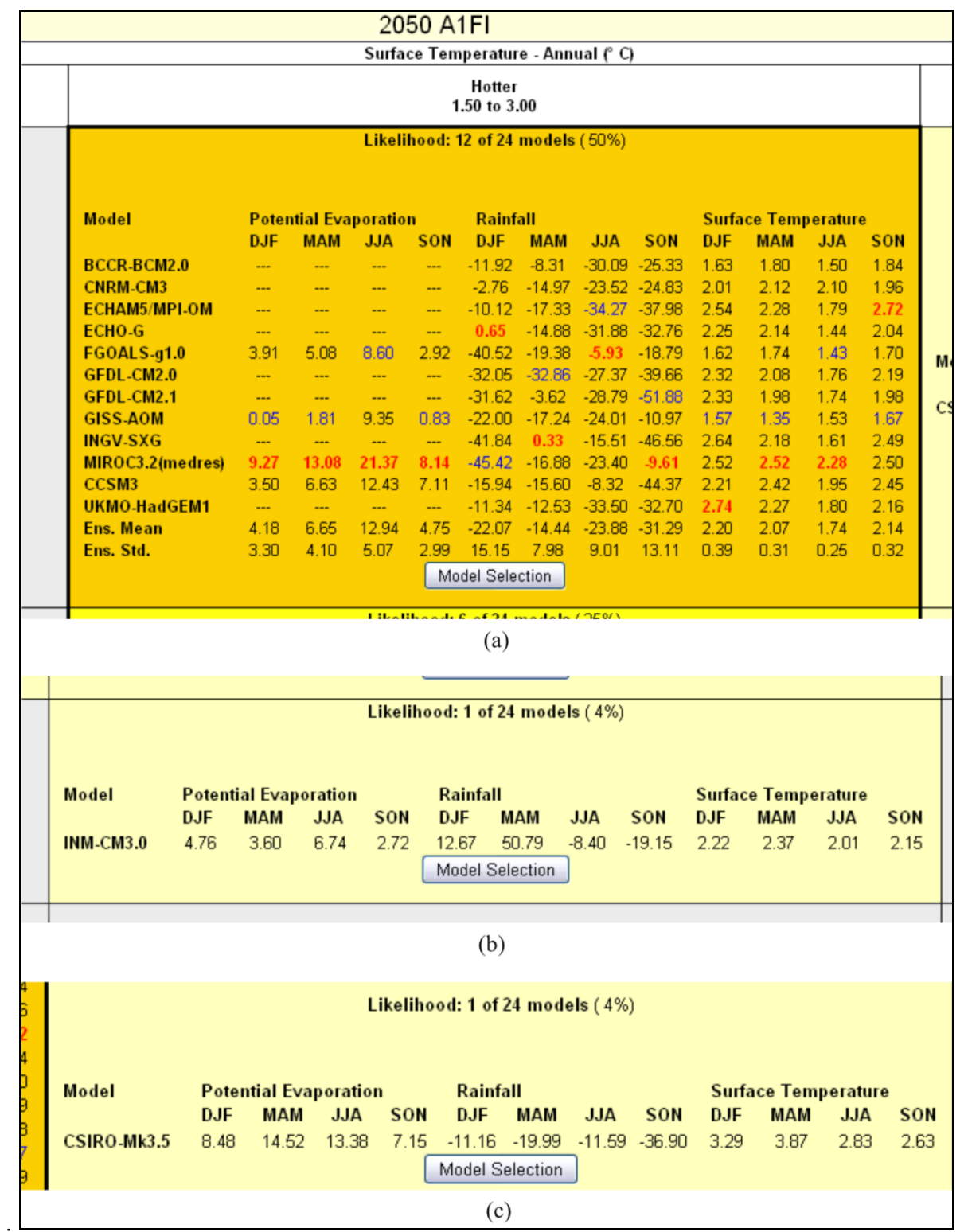

Figure 3 Model-specific change data from each model within the a) 'most likely' (Hotter and Much Drier), b) 'best' (Hotter and Wetter), and c) 'worst' (Much Hotter and Much Drier) case climate futures for 2050 A1FI. Summer is DJF, autumn is MAM, winter is JJA and spring is SON.

\begin{tabular}{|c|c|c|c|}
\hline \multicolumn{4}{|c|}{ Multi-variate variable ranking } \\
\hline Variable & Season & Rank & Rank Method \\
\hline Potential Evaporation & D.JF & $1 \sqrt{v}$ & mean $v$ \\
\hline Potential Evaporation & MAM & $1 v$ & mean $v$ \\
\hline Potential Evaporation & JJA & $1 v$ & mean $v$ \\
\hline Potential Evaporation & SON & $1 \mathrm{Q} \sim$ & mean $v$ \\
\hline Rainfall & D.JF & $1 \mathrm{Q} \sim$ & mean $v$ \\
\hline Rainfall & MAM & $1 \mathrm{Q} \sim$ & mean $v$ \\
\hline Rainfall & JJA & $1 \mathrm{Q} v$ & mean $v$ \\
\hline Rainfall & SON & $1 \mathrm{Qv}$ & mean $v$ \\
\hline Surface Temperature & D.JF & $2 v$ & mean $v$ \\
\hline Surface Temperature & MAM & $2 \sqrt{2 \sqrt{2}}$ & mean $\sqrt{v}$ \\
\hline Surface Temperature & JJA & $2 v$ & mean $v$ \\
\hline Surface Temperature & SON & $2 \sqrt{2}$ & mean $\sqrt{v}$ \\
\hline \multicolumn{4}{|c|}{ Rank Models } \\
\hline \multicolumn{4}{|c|}{ Model Rankings } \\
\hline \multicolumn{4}{|c|}{$\begin{array}{l}\text { Model Rankıngs } \\
\text { Model }\end{array}$} \\
\hline \multicolumn{3}{|c|}{ FGOALS-g1.0 } & 390.56 \\
\hline 2 & \multicolumn{2}{|c|}{ GISS-AOM } & 547.78 \\
\hline 3 & \multicolumn{2}{|c|}{ CCSM3 } & 622.34 \\
\hline 4 & \multicolumn{2}{|c|}{ MIROC3.2(medres) } & 711.46 \\
\hline
\end{tabular}


Figure 4 Model ranking tool, showing that the "FGOALS-g1.0" model is the most representative (rank 1) of the ensemble mean of the 'most likely' climate future.

For this ranking, surface temperature was rated as lower priority than potential evaporation and rainfall, and each model's results were compared to the ensemble means. Once the models have been ranked, it may be useful to apply knowledge of a model's regional skill (such as its ability to simulate rain-bearing cold fronts over south-west Western Australia) where such information is available. For our example, we will simply use the top ranked ("FGOALS-g1.0") model to represent a 'most likely' climate future for 2050 A1FI. As there is only one model in each of the 'best' and 'worst' case climate futures, model selection is not necessary. The selected models for each case are shown in Table 3.

Depending on the needs of the application, the projected changes may be used directly or the selected models used for dynamical or statistical downscaling to obtain higher resolution information.

Table 3 Representative model for each case, showing the climate futures description and likelihoods.

\begin{tabular}{|c|c|c|c|}
\hline Case & Climate Future & Likelihood & Representative Model \\
\hline 'Best' & Hotter and Wetter & Very Low & INM-CM3.0 \\
\hline 'Worst' & $\begin{array}{c}\text { Much Hotter and Much } \\
\text { Drier }\end{array}$ & Very Low & FGOAL3.5 \\
\hline 'Most Likely' & Hotter and Much Drier & Moderate & \\
\hline
\end{tabular}

\subsection{Step 4: Applying the results}

When reporting and using the results, it is essential they are always presented within the context of the Climate Futures Framework. Failure to do so may lead to under-representing the range of uncertainty among the projections. The range of projections can be readily described with reference to the climate futures (see Step 1, for an example) and this ensures the context of the selected key climate futures is communicated.

The projected changes are relative to the mean climate centred on 1990, which is consistent with the baseline used by the IPCC in their $4^{\text {th }}$ Assessment Report. The current version of the software uses a 30-year (19752004) model baseline. This is important when comparing the projected changes to the 'current' or past climate, either qualitatively or using some form of statistical downscaling based on past climate observations.

In addition, it is important to acknowledge that the individual models, while objectively selected as representative of their associated climate futures, are nonetheless just one simulation of the possible future climate.

\subsection{General comments}

The above hypothetical case study is a relatively simple example that facilitates conceptual understanding of the approach. In practice, it is important to explore the influence of seasonal changes on the climate futures because annual mean changes can sometimes mask seasonal changes, particularly in rainfall. However, once the seasonal changes are understood (and described), it is still often appropriate (and much simpler) to use annual changes to define the climate futures.

Further, where the assessment requires data that permit comparisons among time periods, model selection is more complicated. Ideally, a single model would be used to represent a given climate future at each time period. This is usually achievable but may involve compromises such as selecting a lower ranked model for one time period.

\section{CONCLUSIONS}

The process described in this paper (and Whetton et al. submitted) draws heavily on the authors' many years experience in working closely with end-users of climate projections. We have found the approach useful and popular with end-users.

The advantages of the Climate Futures Framework over more traditional approaches were twofold. Firstly it allows decision makers to obtain climate projections that are representative of the range of projections, but in a way that is directly relevant to their decision-making. By also providing information on the relative likelihoods of the relevant climate futures, the approach is directly applicable to use in risk assessment frameworks. 
Secondly, the selection of a sub-set of models to represent the key climate futures facilitates the provision of internally consistent, multivariate datasets. This reduces the amount of data that needs to be managed. Demand for such datasets is rapidly growing among the impacts and adaptation community.

The Climate Futures software tool is currently being developed into a user-friendly web-tool for Australia. A Pacific version (www.pacificclimatefutures.net), providing projections for 15 developing island nations has been developed as part of the Pacific Climate Change Science Program (www.pacificclimatechangescience.org). The tool has three levels of user access: Basic (available to anyone), Intermediate and Advanced (presently available only to accredited users). The roll-out to all 15 countries was completed in November 2011 and was accompanied by a four-day, face-to-face training course for advanced users.

\section{ACKNOWLEDGEMENTS}

The assistance of David Kent and Tim Erwin of CSIRO Marine and Atmospheric Research in developing the climate futures software is greatly appreciated.

\section{REFERENCES}

Irving D. B., S. E. Perkins, J. R. Brown, A. Sen Gupta, A. F. Moise, B. F. Murphy, L. C. Muir, R. A. Colman, S. B. Power, F. P. Delage and J. N. Brown (2011) Evaluating global climate models for climate change projections in the Pacific island region. Climate Research C1028, DOI: $10.3354 / \mathrm{cr} 01028$

Kokic P, J. Breckling and O. Lübke (2002) A new definition of multivariate M-quantiles. In Statistical Data Analysis Based on the L1-Norm and Related Methods. (Ed. Y Dodge) pp. 15-24. (Birkhäuser Verlag: Basel).

Morton F. I. (1983) Operational estimates of areal evapotranspiration and their significance to the science and practice of hydrology. Journal of Hydrology 66, 1-76.

Nakićenović N. and R. Swart (2000) (Ed.) Special Report on Emissions Scenarios. A Special Report of Working Group III of the Intergovernmental Panel on Climate Change. (Cambridge University Press: Cambridge, United Kingdom and New York, NY, USA).

Pitman A. J. and S. E. Perkins (2008) Regional Projections of Future Seasonal and Annual Changes in Rainfall and Temperature over Australia Based on Skill-Selected AR4 Models. Earth Interactions 12, 1-50.

Smith I. and E. Chandler (2010) Refining rainfall projections for the Murray Darling Basin of south-east Australia - the effect of sampling model results based on performance. Climatic Change. 102, 377-393.

Whetton P., K. Hennessy, J. Clarke, K. McInnes and D. Kent (submitted) Use of Representative Climate Futures in impact and adaptation assessment. Climate Change Letters. 